\title{
Historia y disponibilidad de sal en el Bajo Huallaga. Formas de apropiación de una mina de sal en una comunidad kichwa
}

\section{Miguel Valderrama Zevallos}

iD https://orcid.org/0000-0002-1278-213X

migelvz@gmail.com

A Jaime Pablo Domínguez, o grande mestre.

RESUMEN

Se exploran los vínculos entre los kichwa de la comunidad nativa Callanayaku, en el Bajo Huallaga, y la mina de sal del mismo nombre, a partir de lo que dicen sobre su aprovechamiento en el pasado. En los relatos sobre la historia de esta mina se resaltan varias interacciones entre los kichwa de Callanayaku con personas foráneas (empleados de una empresa de recaudación de impuestos, indígenas de otros pueblos, comerciantes, personal de salud) a través de la circulación de la sal, en especial del intercambio comercial. La disponibilidad de la sal para todos estos grupos es explicada por las personas en la comunidad a través del control sobre las relaciones sociales en las redes de comercio y la distribución de la sal.

Palabras clave: Bajo Huallaga, kichwa, sal, historia, Amazonia, intercambio. 


\section{History and availability of salt in the Bajo Huallaga basin. Ways of appropriation of salt mine in a Kichwa community}

\section{$A B S T R A C T$}

This article explores the links between the Kichwa of the Comunidad Nativa Callanayaku (Bajo Huallaga) and the salt mine of the same name, based on what they say about its use in the past. The stories about the history of this mine highlight several interactions between the Kichwa of Callanayaku with foreign people (employees of a tax company, indigenous people from other indigenous groups, merchants, health personnel) through the circulation of salt, especially commercial exchange. The availability of salt for all these groups is explained by the people in Callanayaku through the control over social relationships in trade networks and the distribution of salt.

Keywords: Bajo Huallaga, kichwa, salt, history, Amazonia, exchange. 


\section{INTRODUCCIÓN}

Este artículo busca contribuir a las reflexiones sobre la territorialidad kichwa en San Martín. Se exploran los vínculos entre las personas de la comunidad nativa Callanayaku y la mina de sal del mismo nombre, en función de lo que estas dicen sobre su aprovechamiento en el pasado.

Callanayaku es una de las catorce comunidades nativas ${ }^{1}$ kichwa del distrito de Chazuta (provincia y región San Martín), ubicada a hora y media en bote a motor de la capital distrital. Esta zona es considerada como el Bajo Huallaga ${ }^{2}$, aunque en términos del paisaje circundante, Callanayaku se localiza en la zona de transición entre las últimas estribaciones de la cadena nororiental de los Andes ${ }^{3}$ (con picos que se elevan hasta los 2000 metros sobre el nivel del mar) y la llanura

1 Este proceso de reconocimiento oficial de la mayoría de los centros poblados kichwa en el Bajo Huallaga comenzó alrededor de 2009, promovido por la Federación de Pueblos Indígenas Kechwa de Chazuta (FEPIKECHA) y la Federación de Pueblos Indígenas Kichwa del Bajo Huallaga de la región San Martín (FEPIKBHSAM), dadas las presiones territoriales y el escenario de posibilidades para enfrentarlas (Chaparro y Valderrama, 2017; Egerlid, 2015; Perez, 2017; Sevilla, 2013). Callanayaku forma parte de la FEPIKBHSAM.

2 «Bajo Huallaga» es el nombre local para el área del río Huallaga y sus afluentes, que se extienden desde la provincia de San Martín — en la región San Martín — hasta la desembocadura del Huallaga, en el río Marañón, en la provincia de Alto Amazonas, región Loreto. En esta amplia área se ubican las ciudades, Chazuta, Pongo de Caynarachi, Barranquita, Huimbayoc, Papaplaya, Balsapuerto, Jeberos, Yurimaguas y Lagunas.

3 En ambas márgenes del río Huallaga, entre la ciudad de Chazuta y el centro poblado Achinamisa, las zonas de montaña se encuentran dentro de dos áreas naturales protegidas. En la margen izquierda, el Área Regional de Conservación Cordillera Escalera, creada en 2005, es administrada por el Proyecto Especial Huallaga Central y Bajo Mayo, del gobierno regional de San Martín. En la margen derecha, el Parque Nacional Cordillera Azul, creado en 2001 y administrado a través de una asociación público-privada entre el Servicio Nacional de Áreas Naturales Protegidas (SERNANP), asignado al Ministerio del Medio Ambiente, y la ONG Centro de Conservación, Investigación y Manejo de Áreas Naturales (CIMA). En ambos casos, existen restricciones en el uso de las zonas de caza tradicionales y el aprovechamiento de recursos para la población de las comunidades nativas, así como varios obstáculos administrativos y legales para que soliciten la titulación comunal de estas zonas de uso tradicional (Chaparro y Valderrama, 2017). 
aluvial, conocida como selva baja. Todavía en los alrededores de Callanayaku, el paisaje es montañoso y el río torrentoso, con innumerables rápidos o malos pasos (principalmente el Pongo de Aguirre). A solo una distancia de una hora río abajo, el paisaje cambia a planicie y el río es más ancho y sinuoso.

Las familias de Callanayaku (un aproximado de setenta) se dedican principalmente a la agricultura en chacras de pequeña escala (donde cultivan plátano, yuca, frejol, maíz, arroz y maní), a la pesca (con un periodo intenso durante el tiempo de mijano $^{4}$ ), a la caza de animales del monte y a la crianza de animales menores. Las familias también cultivan en sus huertas caseras diferentes tipos de ajíes y algunas plantas que sirven en la pesca y como remedio. Del bosque, aprovechan diferentes tipos de árboles y palmeras, sea para la construcción de sus viviendas, para preparar medicinas con sus hojas, cortezas o resinas, para vender la fibra y frutos, entre otros usos.

El núcleo de viviendas en Callanayaku se ubica en un promontorio en la margen derecha del río Huallaga. Para desarrollar sus actividades de agricultura, caza, pesca y aprovechamiento de árboles, las familias ocupan también varios sectores — en ambas márgenes del río - , tanto en el entorno de su centro poblado como a días de camino en la montaña. Además, a los alrededores se encuentran depósitos de sal mineral que han sido y son aprovechados por la gente de esta y otras comunidades del Bajo Huallaga. La fuente (o la «mina», como la denominan en Callanayaku) de sal que actualmente sigue siendo aprovechada se encuentra en la margen izquierda del río. Las labores de obtención de la sal se realizan durante la época de verano (entre los meses de junio y setiembre), cuando se reduce el caudal del Huallaga y deja al descubierto la playa donde, con la remoción de partes de este lecho, las personas encuentran las vetas de sal. El trabajo de obtención de sal es una labor en la que participan varios grupos familiares de la comunidad. Pasada la temporada de verano, con el aumento del caudal producto de las lluvias, la mina de sal queda sumergida bajo el agua. Durante este periodo, la sal se regenera.

Muchas personas en la comunidad estarían de acuerdo con la afirmación de que Callanayaku se encuentra encima de depósitos de sal o, como elocuentemente

4 El mijano se desarrolla entre los meses de mayo y septiembre, que corresponden a la época de verano y el estiaje del río Huallaga. El mijano se caracteriza por la abundancia de peces que surcan el río Huallaga desde las zonas de planicie amazónica. Este periodo dentro del calendario suele ser de dedicación intensiva a la pesca. Una vez capturados, los peces se conservan con sal para su mantenimiento por varios meses. También se venden en los mercados de Chazuta y de ahí a otras ciudades como Tarapoto. 
me indicó doña Luzdina — quien ha vivido en el pueblo durante varias décadas«encima de la sal somos nosotros». La presencia de varios afloramientos de sal en diferentes sectores de la comunidad (sea como sal gema o como emanaciones de agua salada sobre la tierra) sustentarían esta afirmación.

El aumento de familias y crecimiento del poblado en los últimos cincuenta años obedecieron principalmente a las actividades de obtención de la sal. Todas las familias vinculadas con esta actividad proceden de otras zonas de la Amazonía peruana (hay personas de Iquitos, por ejemplo), de Chazuta y otras comunidades kichwa del Bajo Huallaga.

Visité Callanayaku en la temporada de verano (entre junio y setiembre) de 2018. Meses antes, durante mi primera visita ${ }^{5}$, había tomado conocimiento del aprovechamiento de la sal y de su importancia para las personas de la comunidad vinculada con el consumo doméstico, la preservación de peces y el comercio regional. Sin embargo, fue en el periodo de verano de 2018 en el que me propuse sistemáticamente profundizar en este tema ${ }^{6}$.

Al interrogarlas sobre la mina de sal, las personas en Callanayaku usualmente me referían a situaciones y acontecimientos que habían tenido lugar en el pasado. Así, no fue necesario que les propusiera de forma explícita el tema de la historia del aprovechamiento de la mina, al menos no en los primeros diálogos. A menudo, valía acompañarlos en los ratos de observación del río (habitual en las primeras horas de la mañana y en la tarde) para que surjan frases como «las balsas ya estarían haciendo cola aquí para bajar con sal», «en otros tiempos, esta parte del río estaría llenito de balsas», «antes había un almacén del Estado donde se guardaba la sal», «antes venían indios de otras tribus con sus botecitos a llevar esta sal» y así por el estilo, que daban pie a conversaciones sobre sucesos en décadas anteriores.

Luego de un tiempo, y después de escuchar repetidas veces relatos sobre ciertos acontecimientos en los que incidían las conversaciones sobre la sal, decidí preguntar - sobre todo a las mismas personas - por mayores detalles. Sabiendo mejor de qué iba el tema de la sal, comencé a proponerles que me contasen «la

5 Realizando un proceso corto de cartografía social con apoyo del Centro Amazónico de Antropología y Aplicación Práctica y la Federación de Pueblos Indígenas Kichwa del Bajo Huallaga San Martín.

6 La investigación se desarrolló para obtener el título de magister en Antropología en la Universidad Federal Fluminense (Niterói, Rio de Janeiro), y los resultados fueron presentados en 2019 bajo el título O sal da Montanha. Notas etnográficas sobre relações de domínio e a circulação do sal numa aldeia do Bajo Huallaga na Amazônia peruana (Valderrama, 2019). 
historia de la mina de sal», o incluso «la historia de la sal», en cuyo caso las personas respondían con versiones de los temas bastante consistentes entre sí. De hecho, las personas de más edad tenían mucho que decir en estos relatos, dado que vivieron cuando eran jóvenes - e incluso niños - los eventos relatados. Las más jóvenes, incluso sin haberlos presenciado, conocían varios de los tópicos gracias a sus parientes mayores.

En el presente artículo se brinda un análisis histórico de los significados que tienen estos relatos con respecto a las formas de apropiación y control territorial kichwa. Así, fundado en la importancia que dan las personas a sus propias narraciones sobre la disponibilidad de sal a lo largo del tiempo, examinaremos la naturaleza del vínculo de la población de Callanayaku con la mina del mismo nombre.

Señalar que el vínculo entre pueblos indígenas y su territorio tiene un carácter histórico no es nada nuevo en los estudios sobre grupos amazónicos. La dimensión temporal de la relación con el territorio ha sido bastante explorada en la producción académica (Hill, 2011; Kohn, 2007; Rappaport, 2004; Rival, 2012; Santos Granero, 2004a) y ha sido un recurso fundamental en informes y peritajes antropológicos a la hora de sustentar la obligatoriedad de restitución de territorios a las actuales poblaciones indígenas en varias partes de la Amazonía.

Por otro lado, en el pensamiento kichwa, una forma de manifestar apropiación o control de un lugar $u$ objeto es la que se encuentra asociada a la idea de disponibilidad. En el idioma kichwa, el sentido de poseer algo se encuentra más vinculado con el verbo en español «haber» que con el verbo «tener». Siempre que la posesión no sea indicada a través del sufijo -yuk (como en wasiyuk, «que tiene casa»), en kichwa se recurre al verbo tiyay. Así, el sentido de la frase «Ñukanchikpa kachita tiyan» no sería propiamente «nosotros tenemos sal», como en el castellano, sino «de nosotros hay sal» ${ }^{7}$. Este artículo se basa en la idea de que esta forma de señalar una posesión o control encuentra correspondencia con las formas de comprensión de la historia de la mina de sal contada en Callanayaku.

Este trabajo se divide en cuatro secciones: en la primera, realizaré un recuento del lugar de la sal en los procesos socioeconómicos del Bajo Huallaga desde la época prehispánica, que servirá a los lectores para introducirse en algunas dinámicas centrales de la región. En la segunda sección, describiré sintéticamente lo

Agradezco al profesor Jaime Doherty Vonah por enseñarme estas y otras maneras diferenciales del sentido de las palabras en kichwa de San Martín respecto del español, así como las precisiones hechas por el profesor y abogado kichwa Marco Antonio Sangama Cachay con relación al uso del verbo en cuestión. 
que la gente de Callanayaku considera significativo en su historia sobre la mina de sal. En la tercera sección presentaré reflexiones orientadas a la comprensión de los significados de la historia en lo relativo a su vínculo con el recurso y el lugar.

\section{CONTEXTOS DE LA SAL EN LA AMAZONÍA NOROCCIDENTAL}

Diversos estudios muestran la relevancia de las redes comerciales de larga distancia entre grupos indígenas de la Amazonía noroccidental (Oberem, 2004; Reeve, 1994; Scazzocchio, 1978; Taylor, 1999). Esta área, que se extendía entre los ríos Napo — con sus tributarios (río Curaray y río Villano)—, Pastaza, Marañón, Amazonas, Huallaga, e incluso la parte baja del río Ucayali, ha sido caracterizada como de intenso comercio desde épocas precoloniales. Las redes comerciales en este ámbito y a lo largo del periodo de 1538-1638 (Reeve, 1994) eran principalmente dominadas por grupos tupi-omaguas en el río Napo y cocamas en el Marañón. Estos grupos basaban su preminencia en el control del intercambio regional de telas y canoas y en una postura agresiva con los pueblos de esta red. En los siglos siguientes, las estrategias y redes comerciales tupi se volverían claves para los intereses de la expansión colonial.

Por otro lado, se sabe que los grupos que habitaban la cuenca del Huallaga desarrollaron intercambios de bienes entre sí (Scazzocchio, 1978, 1981) y con poblaciones asentadas a lo largo de los otros ríos en la cuenca del Amazonas (Santos Granero, 1985, 1992). Complementariamente a esta red comercial —al menos desde el final de la era precolonial—, se desarrollaba una modalidad de intercambios comerciales recíprocos con grupos de las zonas altas denominada rescate, la cual permitió a estos obtener recursos de las áreas amazónicas que no ocupaban $^{8}$ (Santos Granero, 1985).

Desde la segunda mitad del siglo XVI, los misioneros españoles y las fuerzas militares - en acciones de conquista algo tardías para esta época (Santos Granero, 2004b) - se adentraron a la región de «indios infieles» e iniciaron el contacto con estos, el que había sido esporádico desde la creación de las primeras ciudades en la cuenca del río Huallaga: Huánuco en 1539 y Moyobamba en 1540. Las misiones administradas por los jesuitas fueron la expresión más clara del poder

Vale la pena mencionar que el «rescate», para estos grupos del llano, era una práctica complementaria al «control vertical de un máximo de pisos ecológicos», según la noción sugerida por John Murra (1975), otra modalidad de acceso a recursos de diferentes ambientes geográficos mediante la ocupación de colonias de población andina (que Murra llama archipiélagos). 
colonial en el contexto del Huallaga entre los siglos XVII y XVIII (Marzal, 1984; Negro, 2000; Torres-Londoño, 2012). Esta orden, por encargo del gobernador de Maynas ${ }^{9}$, estableció una misión en Borja en 1638 y después otras siete durante un período de cinco años, ocupando varios puntos del Marañón y afluentes hasta la desembocadura del río Huallaga. Hacia la segunda mitad del siglo XVII, las misiones se extendieron hasta el río Paranapura, cambiando también la capital de las misiones, anteriormente Jeberos (afectada por el levantamiento de los indios cocama), a Santiago de La Laguna, en el río Huallaga, en 1663 (Negro, 2000). En 1686 se habían creado veinte misiones, nueve de las cuales eran anexos de Santiago de La Laguna (Santos Granero, 1992, p. 165), aunque varias de ellas no duraron mucho o fueron abandonadas (Torres-Londoño, 2006, p. 17).

El desarrollo de las misiones, fundado en una estrategia de contacto, alianzas para el intercambio y protección a los indígenas locales (Reeve, 1994; TorresLondoño, 2007), demandó un conjunto de anclajes económicos, para los cuales los conocimientos de los grupos nativos fueron esenciales, especialmente los referidos a la provisión de recursos en el bosque, la identificación de áreas adecuadas para establecer villas y el despliegue del intercambio comercial (Reeve, 1994). En lo que respecta a los canales de intercambio indígena, estos fueron replicados y controlados por los jesuitas, lo que sirvió para la difusión de bienes europeos y la expansión de los bienes valorados por los indígenas, tales como la $\mathrm{sal}^{10}$ y el veneno (Cipolletti, 1988) ${ }^{11}$.

En la cuenca del Huallaga, las redes comerciales pudieron extenderse desde la región de los cocama (en la desembocadura del Huallaga) a través de intermediarios como los muniches (desde el río Cahuapanas, afluente del río Marañón), siguiendo el área habitada por los tabalosos y lamistas, hasta la parte superior del río Huallaga, el área de Cholones e Hibitos, estos en una red comercial con Cajamarquilla, en la sierra de la actual región de La Libertad (Reeve, 1994).

El «descubrimiento» de la sal de la Montaña para las misiones, a mediados de siglo XVII, se dio gracias a las noticias dada por los indios cocama sobre una salina ubicada a una distancia de quince días, según sus métodos de medición,

9 Como consecuencia de una rebelión de los indios maynas cuya represión militar española fue muy violenta (Torres-Londoño, 2007).

10 Cabe indicar que el intercambio de bienes como un eje clave de la economía colonial tuvo un correlato en las formas de clasificación social entre indígenas «cristianos» o «civilizados» que, entre otras cosas, aceptaban la sal y la vestimenta entregados por los jesuitas, y los indígenas «salvajes» que las rechazaban (Barclay, 2001).

11 De modo más general, se puede consultar a Scazzocchio (1978) para comprender los cambios y la permanencia del circuito de intercambio en la Alta Amazonía. 
desde La Laguna hasta los «Cerros del Pongo» (posiblemente refiriéndose al Pongo de Aguirre) en el río Huallaga (Chantre y Herrera, 1901). Con esta sal, fue posible abastecer a toda la misión Maynas ${ }^{12}$ (Chantre y Herrera, 1901, p. 622). Aparentemente, tanto dentro del alcance de la administración colonial como de las misiones, esta zona del Huallaga era de poco interés debido a que las gobernaciones vecinas de Lamas y de Borja no habían definido incluirla dentro de alguna de estas jurisdicciones. Solo luego del descubrimiento de la salina, mediante una disputa elevada hasta la Real Audiencia de Lima, se resolvió la incorporación de la salida a la jurisdicción de Borja, otorgando a los misioneros de Maynas el derecho de reunir en las misiones a los indios que se descubriesen en la zona (Chantre y Herrera, 1901, p. 623). La provisión de sal para las Misiones fue una actividad enteramente indígena; sin embargo, los padres en cada misión tenían el control sobre la organización del trabajo (que incluía los gastos en provisiones durante la expedición) y sobre su posterior distribución — preferentemente entre vecinos españoles y autoridades civiles - y almacenamiento. La recompensa de los indígenas por tales expediciones era una parte de la sal, además de cuchillos y veneno entregados en forma de «gratificación» a su trabajo, porque, en teoría, por orden del gobernador, no podían recibir pagos.

A escala macroregional, los indígenas de las villas de los ríos Napo, Tigre y Nanay, así como las misiones de Alto Napo (en Ávila y Archidona), se organizaron de manera similar para enviar a otros nativos a la misión de Omaguas (ubicada en Nauta), a proveerse de sal. Como Reeve (1994) indica, la sal también se distribuyó en las nuevas misiones, así como en Pastaza y Lamas. Una de las posibles consecuencias de las expediciones de la sal fue el abandono de las técnicas de elaboración de condimentos salados con base en las plantas ${ }^{13}$.

Después de la expulsión de los jesuitas en 1767, los comerciantes blancos comenzaron a dominar la red de comercio, que incluía el control de la sal y el veneno curare (Reeve, 1994, p. 130). Aun así, grupos como los quijos realizaron viajes al Huallaga, ya sea por cuenta propia o en servicio a estos comerciantes

12 Poco después, los jesuitas «descubrieron» una mina de sal roja en el río Paranapura, muy utilizada por los Capavanas, Paranapuras, Muniches, es decir, los indios de los ríos Marañón, Paranapura y Shanusi, respectivamente. El padre Chantre y Herrera estimó la abundancia de sal en estos dos depósitos indicando que eran suficientes para proveer «provincias y reinos enteros» (1901, p. 623).

13 Como indicó Oberem (2004), los quijos (grupo de habla quechua en el río Napo) elaboraban sal de plantas en el siglo XVI. Con el establecimiento de la misión de Archidona y el «descubrimiento» de depósitos de sal en el Huallaga, los quijos conocieron también el recorrido para llegar a esa zona. 
blancos (Oberem, 2004, p. 353). La red comercial incluyó también personas del área del río Pastaza y la parte superior del río Bobonaza, como los canelos quichua (Oberem, 2004, p. 354), los ashuar (Karsten, Montano, Iglesias y Dueñas, 2000) y los quichua del río Curaray (Reeve, 1994, 2002) ${ }^{14}$.

Con la independencia, en la segunda década del siglo XIX, las élites políticas de Lima asumieron el proyecto de configurar al nuevo Estado-Nación, dentro del cual la Amazonía cobró gradualmente visibilidad, dado el interés geopolítico de esta zona que, pese a ser considerada tierra desconocida, era estratégica para la soberanía nacional. Los conflictos, principalmente con el Ecuador (independizado en 1830, pero que mantuvo el control de la región de Maynas durante la colonia, hasta 1802) impactaron en las redes comerciales prerrepublicanas, en las que destacaba la circulación de sal. A mediados de ese siglo, la ruta comercial se volvió insegura para los kichwa del Napo, quienes sufrieron persecución y violencia por las fuerzas armadas peruanas (Reeve, 1994, n. 12).

A partir de la segunda mitad del siglo XIX, durante el período de expansión económica del Perú (por la creciente explotación del guano en las islas costeras) y bajo las consignas del liberalismo económico de la época, el gobierno peruano impulsó la articulación del país con el mercado exterior, a través de la navegación a vapor hacia el Atlántico (vía Brasil, con quien firmó un tratado comercial en 1851), en conexión con las áreas de explotación de los recursos forestales en la Amazonía. En consecuencia, zonas como el Bajo Huallaga entraron a participar del nuevo circuito. De esta manera, se intensificó el comercio de tabaco (producido en Tarapoto), aguardiente (fabricado por la población del Huallaga), sombreros de Panamá (elaborados en el Alto Mayo), pescado salado (de las diferentes cuencas del Bajo Huallaga y el Ucayali), así como piedras de sal ${ }^{15}$, por la ruta Huallaga Marañón - Amazonas (Maskrey, Rojas y Pinedo, 1991; Paz Soldán, 1862, p. 698).

14 Estos intercambios indígenas intergrupales se mantuvieron incluso hasta el comienzo de los conflictos fronterizos entre Perú y Ecuador, a mediados del siglo XX. La relevancia de estos viajes de intercambio tiene una reveladora expresión en las tradiciones orales de estos grupos, en los cuales se menciona la zona del Huallaga. Ver Gianotti (1997), Reeve (2002), Duche (2005).

15 Paz Soldán apenas informó sobre el movimiento comercial de la Provincia Litoral de Loreto en la primera mitad del año 1855, en un extracto del informe presentado en la Asamblea Provincial de Pará. Según este extracto, en febrero de ese año 120 piedras de sal fueron importadas a Pará en embarcaciones menores. Sería interesante profundizar sobre el comercio de este bien, que puede dar una idea de la explotación de sal en el Bajo Huallaga en este período y sobre el cual no hay datos disponibles. 
Además, durante el siglo XIX se realizaron viajes de exploración científica a la Amazonía peruana con la intención de identificar recursos y proponer al Estado peruano formas de integración económica de sus lugares y población. Una de ellas fue la del geógrafo peruano Mateo Paz Soldán, quien realizó un viaje por la entonces Provincia Litoral de Loreto (conformada por las cuencas del Huallaga, Ucayali y Marañón), del que dejó descripciones tanto de los recursos forestales, la variabilidad geológica, el curso de los ríos y las minas de sal del Huallaga, caracterizándola como el principal producto mineral de la provincia:

Aunque este material no es de gran valor, las salinas pueden [...] producir una ventaja mayor que cualquier mina de plata, debido al gran consumo que se realiza en la provincia, tanto para uso doméstico como para la preparación de pescado salado (Paz Soldán, 1862, p. 674).

Además de la abundancia de sal en los depósitos de Callanayaku y Pilluana (localizada varios kilómetros río arriba de Chazuta) - de los cuales se abastecían tanto las poblaciones del Huallaga como las de Amazonas y Ucayali- el geógrafo también consideró que su localización a orillas del Huallaga favorecería una extracción a bajo costo de transporte. Recomendó que el gobierno otorgase los depósitos a alguien para que los explotara, con lo cual se podría obtener un ingreso para invertir en la apertura y construcción de carreteras en la provincia (1862, p. 675).

Bajo una idea similar, Antonio Raimondi ${ }^{16}$ —un naturalista italiano que años antes de Paz Soldán había recorrido varios lugares del Bajo Huallaga — indicó la importancia de desarrollar la agricultura y las industrias como los sombreros de Panamá, los pescados salados y la extracción de sal, pero veía mal que la mano de obra indígena estuviese dedicada al transporte, sirviendo de «bestias de carga» y como bogas (conductores de embarcaciones), tareas que, además, no conseguían cubrir la demanda del transporte. Por esta razón, recomendó la mejora del servicio de navegación a vapor y las rutas a los centros de comercio (Raimondi, 1942).

16 Antonio Raimondi fue un naturalista que desarrolló un ambicioso trabajo sobre la historia y la geografía del Perú (publicado con el título El Perú). Recibió asistencia económica del Estado peruano y realizó consultorías para este último sobre explotación de recursos (Silva, 2016). Por ello hizo estudios para el Estado para promover actividades económicas en los lugares que visitó. En su primer estudio publicado, Raimondi trató sobre la Provincia de Loreto, un área que incluye el Bajo Huallaga. 
En 1896, como parte de la introducción de varios impuestos al consumo, el gobierno peruano promulgó la ley de creación del estanco de la sal ${ }^{17}$, bajo la justificación de contar con respaldo económico para «rescatar» a las provincias de Tacna y Arica, entregadas por diez años a Chile, después de la guerra con ese país. Con el estanco ${ }^{18}$, el Estado peruano prohibió la libre explotación de las salinas e impuso su monopolio en la venta de sal, llegando a impedir, como consecuencia, que indígenas de varias zonas andinas del país mantuvieran el control del comercio de este recurso. A partir de 1901, empresas de la élite limeña fueron nombradas para administrar la recaudación del estanco (Contreras, 2009, p. 382).

A diferencia del sur andino ${ }^{19}$, las salinas de la Amazonía, incluido la del río Huallaga, recién pudieron ser controladas a partir de 1929 con la creación de la Caja Nacional de Depósitos y Consignaciones (Caja de Depósitos y Consignaciones (Perú) y Departamento de Recaudación, 1954), una entidad formada por bancos privados (a través de la Asociación de Bancos) y responsable, hasta 1966, de organizar la recaudación de impuestos en todo el país para el erario público, para lo cual cobraba una comisión muy elevada por esta tarea: entre un tercio y un cuarto de lo recaudado (Zapata, 2006, p. 149). Así, con la Caja de Depósitos y Consignaciones se dio inicio a la explotación de las salinas del Huallaga para abastecer al departamento de Loreto, que anteriormente importaba sal (Caja de Depósitos y Consignaciones (Perú) y Departamento de Recaudación, 1954, p. 18608).

Las primeras décadas del siglo XX estuvieron marcadas por la consolidación de la ruta comercial por el Atlántico, así como por la implementación de la estructura estatal dentro del ámbito del Bajo Huallaga. En el período anterior

17 El estanco de la sal no era nuevo. Anteriormente se había implementado en la época colonial, a principios del siglo XVII, como una forma de controlar el uso intensivo de este recurso para el refinado de plata. Con la independencia (en 1821), el único recurso que se detuvo fue el guano, hasta 1896 (Contreras, 2009). El estanco reemplazó a la «contribución personal», pero manteniendo la recaudación de impuestos para la mayoría de la población sin perjudicar los intereses de la élite económica del país (Contreras, 2009).

18 El impuesto fue de cinco centavos por kilogramo de sal doméstica y un centavo por kilogramo de sal industrial, lo que equivale al doble del precio de la sal en la salina.

19 Desde el comienzo, la implementación de la recaudación del estanco generó revueltas en la provincia de Huanta y en el distrito de Maras, ambas en las zonas sur andinas, en las que existían salinas explotadas por los indígenas. Aunque la regulación de la ley (establecida seis meses después de promulgada la ley) exoneraba de impuestos a los indígenas de las comunidades acostumbradas a extraer sal siempre que fuese para su consumo personal, las revueltas fueron expresión del efecto de esta medida en el comercio de la sal, dominado por los naturales de esas zonas. Para detalles de los levantamientos, ver Ruiz de Pardo (2005). 
a la apertura de vías terrestres que conectan esta parte de la Amazonía con la costa norte peruana (a partir de la década de 1980), el flujo de bienes y personas se orientaba del río Huallaga hacia la ciudad de Yurimaguas (provincia del Alto Amazonas, región de Loreto) e Iquitos, ciudades vinculadas al circuito de caucho, pescado salado, zarzaparrilla, barbasco, algodón, ganado, aguardiente, entre otros productos comerciales producidos en la Amazonía peruana (incluido el Bajo Huallaga), desde principios del siglo XX. La interconexión entre estos lugares se mantiene en la actualidad ${ }^{20}$, aunque en varios casos hay rutas terrestres más rápidas y menos costosas. Los habitantes de Callanayaku proveían de sal a las haciendas ganaderas, reforzando esta actividad económica en la Alta Amazonía. Además, muchos comerciantes que pasaban por Callanayaku en dirección a Yurimaguas e Iquitos, compraban piedras de sal como mercancía para venderlas en esas ciudades.

Por otro lado, varias políticas estatales en el campo de la salud pública generaron cambios significativos en relación con la explotación y comercio de sal en las minas del país, y en la Amazonía en particular. Desde la década de 1970, el gobierno peruano venía promulgando normas que obligaban a yodar la sal para el consumo humano y anima ${ }^{21}$. En ese momento, la extracción, industrialización y comercialización de sal estaba monopolizada por la Empresa de la Sal (Emsal), una empresa estatal. En la década de 1990, Emsal tenía quince campos salinos en varias zonas del Perú. Aproximadamente el $70 \%$ de su producción de sal yodada se realizó en la costa peruana (en la provincia de Huacho, al norte de Lima), pero era insuficiente y no garantizó el consumo en áreas consideradas endémicas para enfermedades por deficiencia de yodo, ubicadas en la región andina — aquellos con mayor endemismo - y en la Amazonía peruana, considerada de endemismo leve (Pretell Zárate, 1989).

Desde la década de 1980, el Estado peruano implementó gradualmente políticas para erradicar las enfermedades por deficiencia de yodo, principalmente bocio y cretinismo, al reconocerlas como problemas de salud pública. El Programa Nacional de Erradicación de los Desórdenes por Deficiencia de Yodo (PRONEDDI), creado en 1994, fue el corolario de la intervención estatal en

20 Por ejemplo, las poblaciones de los distritos del Bajo Huallaga tienen que trasladarse a Yurimaguas porque están comprendidas dentro de la jurisdicción del Ministerio Público, con sede en esa ciudad.

21 En Perú, la sal de yodo para consumo humano y animal ha sido obligatoria desde 1969, según el Decreto Ley 17387, que fue regulado en 1971. 
tales enfermedades ${ }^{22}$. En los años siguientes, el Estado peruano había logrado acercarse a la erradicación de estas enfermedades y era considerado una intervención modelo en América Latina (Pretell Zárate y Higa Yamashiro, 2008), principalmente por la estrategia de universalización de la sal yodada. Con este fin, PRONEDDI se enfocó en mejorar la disponibilidad de sal yodada, promoviendo su consumo, controlando la calidad de la sal yodada y eliminando enfermedades por deficiencias de yodo.

Dado que los pequeños y grandes productores estaban ubicados en la costa y el altiplano peruano, con los cuales se desarrollaron las estrategias para la producción y comercialización de sal yodada, las principales estrategias del programa en las áreas amazónicas fue controlar la calidad de la sal para la comercialización. Así, se establecieron operativos de control para reprimir la venta de sal no yodada, bajo la responsabilidad de las autoridades sanitarias locales, subprefecturas, Ministerio Público y la Policía Nacional (Perú. Ministerio de Salud. Dirección General de Salud de las Personas. Programa Nacional de Prevención de Deficiencias de Micronutrientes, 1998). A su vez, el control de calidad de la sal se realizó principalmente en tiendas, mercados y hogares, utilizando un kit de detección de yodo llamado yoditest, un gotero que contenía un reactivo líquido que, al ser aplicado sobre una porción de la sal, cambiaba de color a morado, más o menos intenso según la presencia de yodo. Estos yoditests fueron entregados a los establecimientos de salud, tanto a los empleados como a las autoridades locales, maestros, Policía Nacional y otras autoridades. Los establecimientos de salud tenían la obligación de llevar a cabo al menos estas actividades de vigilancia y control, independientemente de si estaban ubicados en áreas de «riesgo» ${ }^{23}$ (Perú. Ministerio de Salud. Programa Salud Básica para Todos, 1996). En el caso de Callanayaku, la implementación de estas estrategias tuvo como implicancia que la explotación y el comercio de sal de la mina se restrinjan y su consumo sea

22 En la década de 1950, se creó el Departamento de Bocio Endémico para tratar esta enfermedad como un problema de salud pública, en el contexto posterior a la Conferencia Latinoamericana de Nutrición en Río de Janeiro ese mismo año. En 1960, este Departamento se integró al Instituto de Nutrición, bajo el nombre de Departamento de Profilaxis del Bocio Endémico, que desarrolló una investigación en 1967. En 1983, el Ministerio de Salud creó la Oficina de Bocio Endémico (DS 047-83 -SA), más tarde llamado Programa Nacional de Control del Bocio y Cretinismo Endémico (PRONABCE) en 1987. Durante todo ese tiempo, y pese a los cambios de denominación y realineamientos, la intervención jamás fue interrumpida.

23 El Ministerio de Salud del Perú tiene por tradición desarrollar protocolos y manuales de procedimientos estándar para todos los establecimientos de salud de todo el país. 
prohibido. Con ello, la circulación de sal fue perdiendo la importancia que tenía dentro de la economía y las dinámicas sociales de las familias en Callanayaku.

\section{HISTORIA DE LA SAL EN CALLANAYAKU}

En esta sección describiré la circulación de la sal de la mina de Callanayaku en el siglo XX a partir de los relatos de las personas de esa comunidad. Los momentos en la historia serán presentados a manera de síntesis en subsecciones, con el propósito de mostrar el motivo, temas y actores principales en los acontecimientos narrados.

\section{La Caja de Depósitos y Consignaciones y su dominio sobre la sal de Callanayaku}

En Callanayaku recuerdan que, tiempo atrás ${ }^{24}$, se estableció un almacén de la Caja de Depósitos y Consignaciones en las proximidades del poblado (así como varias otras instaladas en lugares como Nauta o Yurimaguas, que varios de las personas mayores conocieron por sus viajes para la venta de sal). En Callanayaku se refieren a la caja como «una empresa del Estado», «el Banco de la Nación» o, más comúnmente, haciendo referencia a su ubicación en la comunidad («aquí había un almacén del Estado...»). Antes de la caja, quienes «sacaban sal» ${ }^{25}$ de la mina de Callanayaku era la familia de doña Rogelia Pizango Tapullima, hoy una de las personas de mayor edad en la comunidad. Aunque en aquel tiempo era una niña, todavía recuerda bien el desarrollo de las labores de sus padres y hermanos para la obtención de sal. Doña Rogelia resalta en su relato el hecho de que la sal era «libre», ya que, según ella, la mina «no tenía a nadie» y «cualquiera podía sacar» sal. Callanayaku se conformó, según doña Rogelia, a razón de la visibilidad que alcanzó el comercio impulsado por sus abuelos y su padre en el Bajo Huallaga, producto de la obtención de sal en la mina. Así, con la llegada de parientes - tanto de Chazuta como de otros poblados de la cuenca del Bajo Huallaga-, se construyeron nuevas casas y se habilitaron más espacios de cultivos.

En Callanayaku interesa menos el papel de la caja como entidad de recaudación - mencionado en el apartado anterior - que la actuación de sus encargados en el control de la circulación de sal en el Bajo Huallaga. Según las personas, este

\footnotetext{
24 Si alguna referencia es necesaria, esta parte de los relatos podrían remitir a los años del segundo tercio del siglo XX.

25 Es la forma genérica con la cual en Callanayaku se refieren a la colecta de la sal en la mina.
} 
control (en la vigilancia, confiscación, transporte y consumo) era evidente a partir de varias acciones y comportamientos de los empleados de la caja en relación con la disponibilidad de sal para la población. Los empleados a los que se referían fueron los funcionarios designados sucesivamente por la entidad ${ }^{26}$ para administrar la recaudación de la salina de Callanayaku. Nadie más que los empleados de la caja — según me contaron- podía autorizar la compra, distribución y venta de sal. «Esta sal era de ellos, de la caja, ellos disponían. Así quedaban con ellos... tú tienes tu negocio, tu dispones, pues», me explica doña Rogelia.

El almacén de la caja fue construido en un recodo del río, al frente de la mina de sal, a la otra orilla del Huallaga. Antes de que el almacén estuviera en ese lugar, estaba ubicado cerca del segundo puerto de Callanayaku, unos metros río arriba. Este cambio es atribuido a la mejora de la visión de los funcionarios a la ruta de las balsas y embarcaciones no autorizadas, que descendían por el río Huallaga con sal de contrabando de la salina de Pilluana (provincia de Picota).

Para las actividades de confiscación, los empleados contaban con una persona de la misma comunidad que hacía las veces de vigía, controlando las balsas de sal de contrabando que intentaban pasar durante la noche. Los cargamentos de sal confiscados eran llevados al almacén. «Este era el lugar más temible, Callanayaku, nadie tenía como pasar, ni para dónde...», me explicó don Julio Tanchiva. Sin embargo, aquellos que eran detenidos recibían una compensación en efectivo por la sal (claro que menor al precio del cargamento) para retornar a sus pueblos.

A su vez, los empleados de la caja también aplicaron restricciones al consumo de la sal a las familias de la comunidad ${ }^{27}$. Don Julio Tanchiva me contó:

La gente, la población tenía que sacar guía, para que saquen solamente un... $50 \mathrm{~kg}$ para sussu consumo [sic]. Y más no les autorizaban. Pero tenía una

26 En el contexto de esta investigación no conseguí información sobre la estructura organizativa y las formas de designación de personal dentro de la Caja de Depósitos y Consignaciones.

27 No pude profundizar lo suficiente acerca de los mecanismos específicos por los cuales los empleados de la «empresa» entregaban sal para el consumo de la población. Sin embargo, el Reglamento del Estanco de la Sal de 1916 tiene un apartado sobre «concesiones especiales» en el que se indican algunas de las pautas para la entrega a los indígenas de la sal en las fuentes donde solían extraerla, como su inscripción en un «Registro especial» y entrega de una libreta para anotar las fechas de entrega de la sal (una cantidad de $7 \mathrm{~kg}$ de sal por año para cualquier poblador o $46 \mathrm{~kg}$ por año para «pescadores indígenas») (en Caja de Depósitos y Consignaciones (Perú) y Departamento de Recaudación, 1954, p. 18627). Siempre que en Callanayaku se abordaba este tema, las personas me reiteraban la distribución del recurso a través de procesos burocráticos similares. 
facilidad, ellos le decían que deben de sacar su sal y llevar cinco toneladas de sal a entregar a la Caja de Depósito [en Yurimaguas]. Ahí tenían que entregar [...] las 5 toneladas. [...] Entonces, a la plata les pagaban a ellos, al que llevaban... tenía una facilidad que... daba el Estado [sic].

La distribución de la sal de Callanayaku en ese tiempo respondía a un sistema de envíos desde la mina a las ciudades de Yurimaguas, Nauta o Iquitos, donde la caja tenía oficinas, almacenes, o establecimientos autorizados por esta entidad. Se aprovechaban los meses de verano para almacenar bloques de sal y trasladarlos por el Huallaga en invierno. Para los envíos se contrataba a peones de la comunidad, incentivados por los empleados — como mencionó don Julioya que eso les permitía acceder a una mayor cantidad de sal, así como a algunos ingresos económicos. Por mucho tiempo, parientes de doña Rogelia (hermanos, cuñado, esposo y primos) fueron enviados a estas «comisiones». El control sobre el envío se realizaba mediante guías de remisión expedidas en la oficina de la «empresa» (un local cerca del almacén), las cuales indicaban las cantidades de sal (en toneladas) que iban a ser transportadas. Ninguna balsa con carga podía navegar y entregar sal en el destino final sin la guía, la justificación para el pago del peón (en la ciudad de destino), así como el indicador de la formalidad de la carga ${ }^{28}$.

Para mis interlocutores de la comunidad, los empleados eran los «dueños» de la sal, porque a través de ellos se ejercía el control sobre la salina de Callanayaku y el recurso. En total, la intervención de la «empresa» en Callanayaku duró casi diez años. Este dominio está asociado a la noción de mezquindad, según se entiende en la comunidad. De hecho, en varias ocasiones me indicaban que la «empresa» era la que «mezquinaba» la sal, considerando las reglas impuestas para su distribución a las personas de la comunidad, así como los controles que fueron establecidos para no dejar circular otra sal que no fuese autorizada por los empleados.

Sin embargo, a pesar de que los empleados de la caja tenían control sobre la salina y el bien, esto no significó la restricción completa a los kichwa de Callanayaku en su involucramiento en la circulación y el usufructo de la sal. En buena medida, la dinámica de operaciones de la caja dependió de la participación y las motivaciones de varios miembros de la comunidad, principalmente en lo que se refiere a la obtención de sal — pues la mayoría trabajaba en la mina, bajo

28 Un indicador, además, de la artificialidad y arbitrariedad de los procesos para las personas que me contaron sobre ese sistema, ya que en ese tiempo las personas no sabían leer y, por lo tanto, no podían corroborar lo que se indicaba en las guías. 
las órdenes de un contratista de la misma comunidad-, así como del transporte de sal. Además, los viajes de los envíos de sal contribuirían al conocimiento de las rutas de ciudades importantes, que continuaron recorriendo cuando la caja se retiró repentinamente de Callanayaku.

\section{Expediciones comerciales de los indios «alamas»}

Las narrativas locales sobre la sal en Callanayaku muestran el interés de otras poblaciones de la Amazonía por este bien. Así, durante mucho tiempo en la comunidad se presenció la llegada de indígenas de Balsapuerto y de Chazuta, ribereños y comerciantes de Yurimaguas y de Iquitos, todos interesados en establecer intercambios de sus bienes por la sal. Una «tribu de indios» (como es reconocida en Callanayaku), destaca entre los relatos de forasteros, quienes habrían visitado varias veces la mina de sal desde Ecuador entre las décadas de 1930 y 1970: los «alamas».

Se recuerda a los alamas, ayalamas o lambos con dientes negros y por los trazos también negros que tenían pintados en sus caras, brazos, pecho y piernas. Grupos de alamas llegaban a Callanayaku navegando por el río Huallaga alrededor del mes de agosto - en tiempo de verano- en canoas que todavía causan sorpresa debido a su pequeño tamaño, una manufactura diferente de las canoas a las que están acostumbrados en el Bajo Huallaga, según recuerdan actualmente. Hablaban quechua, en un dialecto parecido al de los kichwa de Callanayaku, pero no muy fácil de entender para estos. Algunos de ellos también hablaban - aunque pocoespañol (castellano bola-bola). Además, la gente recuerda que ayudaban con los cultivos de yuca y plátano de algunas personas o iban a buscar animales con los hombres de la comunidad, demostrando su habilidad para cazar. Algunos de ellos tenían conocimientos médicos y ayudaban a curar a algunas personas enfermas o con fracturas de huesos. En ese sentido, habían establecido una buena relación con las personas de la comunidad que las acogían, más allá de las relaciones enteramente de intercambio que describo a en párrafos siguientes.

El grupo de alamas estaba conformado en su mayoría por hombres, aunque siempre llegaban algunas mujeres ${ }^{29}$. En sus viajes, los alamas navegaban por los principales ríos que atraviesan las fronteras entre Ecuador y Perú y que desembocan en el río Marañón y luego surcaban el río Huallaga. Varias personas de

29 «[Venían] más harto hombre. Algunos que querían antojarse conocer, venían con todo, su mujer», me dice doña Rogelia. 
Callanayaku me indicaron que las zonas de procedencia de los alamas serían los ríos Santiago, Morona, Tigre, Corrientes y Pastaza.

Para permanecer en la comunidad durante el tiempo de obtención de la sal, evocan en la Callanayaku, el grupo de alamas tenía que construir sus propios tambos con palos, hojas de yarina y shapaja en las playas del río u otros lugares del poblado, favorecidos por el buen tiempo en verano. Pasaban varios días en la obtención de sal y se iban solo cuando «completaban su carga», al final de la temporada de verano. Posiblemente el número de alamas fue variando durante ese intervalo de cuarenta años. En grupos grandes, en los primeros años, comenzaron a llegar cada vez menos alrededor de la década de 1970. Algunos de los alamas contaban a la población de Callanayaku de sus viajes de tres meses desde sus aldeas.

Los alamas tenían dos actividades principales en relación con la sal: hacían trueque con los productos que traían con personas de la comunidad y «chancaban la sal $»^{30}$, trabajando como peones en el depósito de Callanayaku. Esta última actividad tuvo lugar tanto en la época de la «sal libre» — en la cual los kichwa de Callanayku enseñaron la técnica tradicional de obtención de sal (haciendo canales con agua en las rocas de sal) — como en la época de la Caja de Depósitos y Consignaciones (a través del hermano de doña Rogelia, quien les pagaba con bloques de sal).

Décadas más tarde, los alamas solo traían productos para hacer trueque en el pueblo y no me dijeron si participaban en los trabajos de obtención de sal. Traían telas, redes, harina, frejoles, carne, varias especies de peces, huevos de tortuga, vaca marina, masato de pijuayo y algunos productos de sus zonas como sachapapas, mallkis (retoños de plátano) para cultivo y pequeños plátanos.

La llegada de las pocas embarcaciones de alamas a la comunidad estaba un poco más dirigida a algunas personas con las que tenían una relación de intercambio establecida en varios años de intercambio, como los parientes de doña Rogelia, de la familia Pizango. Después de hacer todo el intercambio, llenaban sus canoas con sal. Durante este período, me contaron que los alamas emprendían el retorno a sus lugares en sus pequeñas canoas, es decir, sin hacer balsas. Finalmente, parece que se terminaron intempestivamente estos viajes por la sal ${ }^{31}$. Doña Luzdina recuerda que, antes de eso, durante un buen tiempo estos viajes se fueron haciendo más escasos, hasta la frecuencia de solo dos o tres canoas en temporada de verano.

\footnotetext{
30 Así denominan en Callanayaku al trabajo de separar bloques de sal en la mina.

31 Me contó doña Luzdina: «Yo también he visto. Después así ¡raz! Nomás ya no venía pues ¡raz! Ya no venía».
} 


\section{Trueque de productos por sal}

El trueque o cambalache por sal es el intercambio que se realizaba en Callanayaku y en el que participaban personas de diferentes poblados y comunidades indígenas de la cuenca del Huallaga. Participaban también comerciantes de Yurimaguas y productores de Shapaja, Juanjui o Huicungo, pese a que cerca de estas dos últimas localidades se encuentra la salina de Pilluana. Este intercambio no era mediado por dinero. El cambalache no se ha practicado durante varias décadas ${ }^{32}$, pero «muchos cambalacheros habían llegado aquí», me dijo doña Luzdina. La comparación con la actualidad ofrece una referencia sobre dicha actividad. Don Gilberto me dijo que hoy en día «poco compran [sal] la gente, no es como antes. Antes venían a buscar sal, traían plátanos, yuca, masato, carne de caza, motelo, aguaje... caramba, llegaban a comprar por sal».

El momento más intenso del trueque era en la temporada de verano hasta el mes de setiembre, cuando las innumerables balsas que buscaban llevar sal por el río se reunían frente a la salina. Como indicábamos anteriormente, Callanayaku era parte de un circuito comercial que involucraba a las ciudades del Bajo Huallaga, como Yurimaguas, y que se extendía a la ciudad de Iquitos. Cualquier persona interesada en hacer el viaje en balsa a estas ciudades se detenía en el pueblo para llevar sal y a menudo dejar como intercambio sus propios productos.

Los productos comúnmente intercambiados eran: carne de caza, masato, plátano, aguardiente de caña y ventisho (jugo de caña fermentado), arroz, frejoles, azúcar, maíz, yuca, papas, huevo de tortuga, taricayas, telas, miel, vino, pescado, gallina, pavo, vaca marina, entre otros. Las cantidades de sal dadas a cambio de estos productos no correspondían a un patrón fijo de equivalencias, solo dependían de lo que el propietario de la sal estuviera dispuesto a entregar por cada producto que podía adquirir ${ }^{33}$. Según don Pedro Babilonia, los cambalacheros buscaban a aquellos que se habían mostrado «más cariñosos» en los intercambios de años anteriores, es decir, aquellos que los dejaban más satisfechos con las cantidades de sal por cada producto ofrecido.

32 Algunos me indicaron que fue durante la década de 1990 que terminó el intercambio; otros, a inicios de la década de 2000, y algunos más, apenas unos años (entre tres y cinco). La variación en las fechas es quizás una muestra del poco interés local en hacer referencia a una cronología exacta.

33 Aun así, me dieron algunas equivalencias, por ejemplo: racimo de plátanos por $40 \mathrm{~kg}$ de sal y un cubo de masato por $100 \mathrm{~kg}$ de sal. 
Incluso en invierno, las personas venían al pueblo a buscar sal, a hacer intercambios o comprar con dinero. Aún hoy en día, las personas de otros comunidades y poblados cercanos que, por diversas razones, pasan por Callanayaku preguntan si tienen sal para llevar. Durante mi trabajo de campo, vi a varias personas que llegaban invitadas a los partidos de fútbol o para conmemorar la patrona del pueblo (en honor a la Virgen de la Natividad, el 8 de setiembre), y aprovechaban la visita para buscar dónde adquirir las piedras de sal.

El cambalache, como me dijeron mis interlocutores, significó para las personas en Callanayaku, en último término, proveerse de diferentes recursos y con eso tener prosperidad. Según cuenta don Julio, «en esa época era la riqueza de la gente, llenábamos la despensa con diferentes granos, maíz blando y duro». Doña Rogelia también me explicó:

Pero era la abundancia de plata. ¡Tooooda cosa lo tenías, toda cosa le tenías! Este [me muestra la tela de su vestido floreado] era en cortes, así, alto. Así, su falda. No comprabas así en metro, sino comprabas así, en brasas [brazadas].

Sin embargo, estos intercambios comerciales de los últimos años no representan para las personas de la comunidad el significado que tuvo el cambalache en otros tiempos.

\section{Viajes comerciales a otros lugares para proveer sal}

Los kichwa de Callanayaku también desarrollaron el transporte de sus propios cargamentos de sal. El circuito comercial de la sal inclúa las ciudades de Yurimaguas, Barranquita, Nauta e Iquitos, y las cuencas de los ríos Shanusi, Caynarachi, Chipurana, Marañón y Amazonas. La venta de sal terminó en la primera mitad de 1990 debido a las prohibiciones del comercio de sal sin yodo, como veremos después.

Los viajes comerciales, durante la mayor parte del siglo XX y antes, se realizaron en balsas de madera de topa. Actualmente solo en contadas ocasiones alguien usa una balsa para viajar. Aunque es más económico, el viaje en balsa requiere experiencia en navegación. Hoy en día, prevalecen los viajes en embarcaciones a motor, lo que significa agregar el valor del combustible al producto que se transporta.

La gente en Callanayaku realizó viajes para el comercio de sal, ya sea contratada como peones por otras personas de la comunidad o como propietarios de balsas. Para navegar en una balsa llevando piedras de sal, se necesitan al menos dos 
personas. En Callanayaku, muchos jóvenes y adultos (incluidas algunas mujeres) hicieron este viaje y recuerdan haber acompañado a sus padres o parientes en la travesía, valorándola como ocasión de magníficas experiencias de conocimiento de las rutas, las personas y los lugares de venta.

Para los viajes, se aprovecha el comienzo del invierno. Nunca fue conveniente esperar el avance de esta temporada, pues el flujo del río se incrementa considerablemente, lo que hace muy peligroso atravesar los rápidos o malos pasos (por ejemplo, el Pongo de Aguirre). Tampoco conviene apurar el viaje aún con la temporada de verano, pues se expone la balsa a choques en el fondo del río o en las ensenadas (de arena o rocas) a lo largo del río Huallaga, cuyo caudal es más bajo en esta época del año. Una balsa demoraba por lo menos tres días para hacer el recorrido: de Callanayaku a Yurimaguas era un viaje de veinticuatro horas, y otras veinticuatro para llegar a Lagunas. A veces las balsas atracaban en cada uno de los pueblos y ciudades del Bajo Huallaga, transformando el viaje en un emprendimiento de intercambio, porque en estas paradas se procuraba obtener otros productos, como frejoles, maíz, pescado por sal o también dinero.

Yurimaguas fue uno de los principales lugares de venta, donde los cargamentos completos de sal podían venderse rápidamente por rematistas que compraban al por mayor. Varios de ellos tenían almacenes de $\mathrm{sal}^{34}$. A su vez, las balsas atracaban y podían permanecer varias semanas, si el interés del propietario de la sal era vender por kilogramos (entre 200 y $300 \mathrm{~kg}$ ). Los compradores eran del área del Bajo Huallaga, de las comunidades shawi, del río Marañón o de la cuenca del Ucayali (de las comunidades shipibo-conibo), todos interesados — según me dijeron- en la sal para sus animales y para preservar la carne y el pescado. En Yurimaguas, la sal también se vendía a empresas lácteas y frigoríficos.

Otro lugar de comercio de sal fue la cuenca del río Chipurana, especialmente en los pueblos de Leche y San José. La desembocadura del río Chipurana (tributario del río Huallaga), cerca de la ciudad de Huimbayoc (la capital del distrito del mismo nombre), se encuentra a algunas horas en balsa desde Callanayaku. Los pueblos mencionados tienen muchas haciendas de ganado y sus dueños buscaban la sal para engordarlo y volverlo fértil. Asimismo, la cuenca del río Caynarachi

34 Don Gilberto: «[Los rematistas] han tenido una casa grande ahí. Pero asimismo también te robaban en el peso. Esos eran mañosos en la balanza, pues. Te robaban unos $100 \mathrm{~kg}$ en cada peso. [...] Esa balanza de plataforma». 
(distrito de Barranquita) era una extensa ${ }^{35}$ área ganadera, al igual que la ciudad de Shukshuyacu ${ }^{36}$.

Como veremos a continuación, esta dinámica comercial de la sal comenzó a disminuir en la primera mitad de la década de 1990. En la actualidad, muchas personas continúan haciendo viajes comerciales, aunque no con la misma frecuencia de antes.

Restricciones al comercio de la sal por la Empresa de la Sal y la política de salud pública

Entre los primeros años de la década de 1990, en Callanayaku se presentaron prohibiciones relacionadas con el consumo y la circulación comercial de sal, como producto de las políticas de salud pública que obligaba a que únicamente se comercie y consuma sal yodada, para así erradicar el bocio y el cretinismo.

En ese momento ya había un puesto de salud y una enfermera en Callanayaku, responsable de la atención en la comunidad de la implementación de diferentes programas de salud establecidos en el país, incluido el Programa Nacional de Erradicación de los Desórdenes por Deficiencia de Yodo (PRONEDDI), creado en 1994. Las personas en Callanayaku recuerdan cómo la sal de la mina fue sometida a escrutinio de diferentes formas. Por ejemplo, recuerdan que el personal de salud - un técnico nacido en la misma comunidad - solicitaba a las madres que trajesen un poco de sal de sus hogares para hacer la prueba con un reactivo (el yoditest), o también visitaba cada casa con el mismo propósito. La recomendación en el centro de salud era hacer también pruebas caseras con gotas de limón que permitieran una reacción similar, un cambio de coloración de la sal de blanca a lila.

En la actualidad, las pruebas para determinar la calidad de la sal se recuerdan como evidencias que demuestran, más que la ausencia de yodo, la presencia de una «química» extraña en un producto que para ellos era y debe ser «natural».

35 No he explorado más sobre las relaciones comerciales en estas áreas (por ejemplo, sobre el número y los propietarios de los fundos, la cantidad de ganado y los tipos de tratos económicos con las haciendas). La ciudad de Barranquita parece ser un importante centro ganadero en el Bajo Huallaga o, al menos, las narraciones confirman que era un punto en la ruta recurrente, así como el hecho de que su plaza principal tiene una vaca como monumento central.

36 La zona conocida como El Aguajal, en las proximidades de la ciudad de Nauta, así como la zona próxima a la ciudad de Tamshiyacu — ambas en el río Marañón, en la región de Loretoeran conocidas por los kichwa de Callanayaku por los robos de las balsas con cargamentos. 
En esta comparación, según la opinión de la gente, se considera que la sal de la mina es de mejor calidad ${ }^{37}$.

No obstante, en Callanayaku parecía absurda la indicación de que podrían padecer de bocio (llamado coto) si no cambiaban de sal. «Jamás vi a nadie con bocio en Callanayaku»o «La gente hemos crecido con esta sal» fueron las palabras que escuché regularmente, mencionadas para desacreditar la promoción de la sal yodada en los centros de salud.

Del mismo modo, para la gente resultaba innecesaria la promoción del uso de sal yodada, tomando en cuenta que esta sal no permite la preservación adecuada del pescado. Muchos me dejaron en claro que, a diferencia de la sal «natural», que hace que el pescado salado se conserve adecuadamente durante varios meses, la sal yodada estropea el pescado, causando rápidamente que la carne tenga mal olor y un color azul ${ }^{38}$.

Simultáneamente, en varios de los puntos de venta, la Policía actuó junto con el personal de los centros de salud, llevando a cabo el control de la comercialización de sal no yodada. En Callanayaku asumen que toda esa intervención, y sus esfuerzos para promover el consumo de sal yodada, respondía a un interés del personal de salud en beneficiarse de las ventas de sal yodada (a cargo de Emsal). En este sentido, la venta de sal de la mina de Callanayaku iba en contra de los intereses económicos involucrados en la universalización de la nueva sal yodada.

Como resultado de este período, la dinámica de venta y extracción de sal no era la misma que antes. Muchos me han dicho que la circulación, tal como era conocida, se acabó. Nadie pagaba los precios de la sal en la mina, cuando la distribución de sal yodada permitió que este producto llegara a mercados y tiendas a un precio más bajo. Además, la prohibición de la sal impidió el tráfico de balsas a las ciudades que integraban la red comercial. También debilitó el trueque de los productos con la sal. Don Gilberto me compartió una reflexión sobre esta transformación:

De ahí, cuando viene la empresa de sal, ya se ha terminado. Bonito era, buen negocio de nosotros, de ahí se terminó. Hemos dedicado a hacer chacra para maizal, ahí nos hemos hecho viejos, ya. Pucha, de aquí teníamos nosotros listo para llevar a Chazuta, Tarapoto. Y de aquí a Yurimaguas también exponiendo tu vida, en el río grande. Ahora te cuesta caro.

37 Don Gilberto me lo explicó así: «Tú ves a la sal de mesa que le dicen, échale un poco de limón. Le hace morado. Tendrá yodo, pues. Yodo le echarán la sal. [...] La sal de aquí no. Es un sal [de] bosque que Dios le ha puesto».

38 Don Custodio: «Comprado este de aquí [me muestra la sal yodada empaquetada que está en la mesa]. Le salaban pescado con sal yodada, azuliiiiito amanecía» (risas). 
A pesar de que la circulación comercial recibió un fuerte golpe, continuó. Al menos en el ámbito del Bajo Huallaga, se siguió buscando sal para salar el pescado en la época del mijano o para preservar la carne de caza. Por esta razón, continuaba vendiéndose en pedidos más pequeños $(500 \mathrm{~kg}$. en promedio, cuando la venta antes de las prohibiciones era de cinco a seis toneladas). Otra consecuencia fue el cambio del consumo en la cocina a la sal yodada, a pesar de que la intervención del PRONEDDI en los Centros de Salud terminó a fines de la década de 1990.

\section{LA DISPONIBILIDAD DE LA SAL Y LA APROPIACIÓN DE LA MINA DE CALLANAYAKU}

En este artículo se brindó información para contextualizar las acciones de algunos de estos actores foráneos relevantes. Así, se ofreció información sobre el Estanco de la Sal y el rol de la Caja de Depósitos y Consignaciones en la recaudación de ese tributo, así como del PRONEDDI en lo referente a su implementación como política de salud pública en el territorio peruano. Eso permitió traer consideraciones sobre proyectos de imposición de regímenes de usufructo y comercio de la sal, así como las normas de control sobre la población y la distribución del recurso. Sin embargo, más allá de esta manera en que factores de índole nacional tuvieron una cristalización particular en el ámbito de Callanayaku, en este artículo buscamos comprender cómo en la comunidad explican las acciones de las personas en relación a la sal de la mina, es decir, el sentido que los kichwa dan, por medio de sus relatos, a los eventos ocurridos y a los efectos atribuidos en sus vidas y en el vínculos con la sal y la salina.

Como indica Salomon, es preciso situar las narraciones y testimonios nativos en el cuadro de tipos de conexiones que las personas hacen de los eventos y de las nociones, metáforas y representaciones que usan para explicarlos (Salomon, 1999, p. 19), incluso si estas formas de producir historia — como también señalan Hirsch y Stewart - no presentan una lógica secuencial o causal, según una concepción occidental de la historia (Hirsch y Stewart, 2005, p. 267). En correspondencia, ya Marilyn Strathern, a partir de eventos de contacto entre europeos y melanesios de Papúa Nueva Guinea en el siglo XIX, reflexionaba sobre tales «conexiones» de eventos (que ella denominó «relaciones estructurales»), las cuales pueden ser expresadas también en los efectos de la acción social (Strathern, 2014, p. 214). La autora sugiere que en contrapartida al esfuerzo de sistematización de eventos considerados como ocurrencias (relacionando eventos de manera secuencial y 
usando un contexto para dar sentido a las acciones sociales), pueden encontrarse relaciones estructurales a partir de los esfuerzos de sistematización de los propios sujetos en cuanto productores de imágenes, es decir, considerando los eventos como performances ${ }^{39}$ : únicamente conocidos por su efecto, su sentido reside en las acciones que son evocadas y no por un contexto que lo encuadra desde fuera (2014, p. 215).

Así, como también afirma Joanna Miller en su crítica al abordaje de Terence Turner sobre los kayapó de la cuenca del Xingú (Miller, 2005), es posible recuperar las percepciones de transformaciones que sucedieron en los grupos amazónicos, siempre que estén referenciadas a sus propias formas de concebirlas. Así, al deparar con el material producto de la memoria de mis interlocutores en Callanayaku (sus testimonios, en primer lugar, aunque también aquello que parece ser en la actualidad el sentido común en relación con lo sucedido), consideré pertinente formular la pregunta sobre qué expresan las personas como hechos históricos significativos en sus relatos.

Los momentos de referencia sobre la mina de Callanayaku se organizan en los relatos kichwa revisados anteriormente a partir del carácter que adopta la disponibilidad de la sal. Todo ocurre como si en el centro de las preocupaciones contenidas en sus relatos se encontrasen las formas como la sal está disponible para su circulación entre las personas de la comunidad y por otros. También lo contrario: las redes de circulación de la sal son consideradas a partir de las acciones que las restringen. Especialmente, se trata no solo de escenarios de control y dominio sobre el bien, sino también sobre las relaciones sociales en el ámbito del intercambio comercial: en el trueque o cambalache, sobre los socios comerciales (como los alamas) y en el transporte fluvial de sal. La posibilidad de la sal de estar o no disponible, además, pasa por las acciones que sostuvieron las personas que se involucraron en su circulación, tanto en el sentido de permitir que esta se llevara a cabo como a su restricción, indicados en Callanayaku bajo la figura antisocial de quien intenta «mezquinar» la sal.

Basado en esta comprensión sobre la disponibilidad del recurso como leitmotiv del vínculo histórico con la sal, propongo algunos elementos para la discusión sobre el dominio de salinas por poblaciones indígenas. Wörrle (1999), quien revisó ampliamente la bibliografía sobre la sal entre indígenas y mestizos en América

39 Cabe señalar que la literatura antropológica sobre los kichwa de la Amazonia ha venido desarrollando reflexiones sobre las formas estéticas como objeto de análisis y comprensión de prácticas sociales (Kohn, 2002; Mezzenzana, 2015; Uzendoski, 2014). 
Latina desde el periodo colonial (en América Central, Amazonía, la costa Pacífico de América del Sur y los Andes), toma como premisa su escasez para comprender la organización social en torno a este bien. Cualquier forma de organización «elegida» por los indígenas (Wörrle, 1999, p. 71) estaría basada en el hecho de que la sal es escasa en las diferentes regiones. Según el autor, estas formas de organización social se pueden situar entre la monopolización del acceso a la sal de los españoles después de la Conquista y de los Estados-naciones (Wörrle, 1999, pp. 57, 97), así como las variadas «respuestas» indígenas, principalmente la explotación multiétnica (en el caso de grupos políticamente independientes y de tendencia igualitaria entre sus miembros) y el control a través de la guerra, bloqueos y también monopolios (en grupos configurados estatalmente y con capacidad militar) $(1999$, p. 57).

El modelo de explotación multiétnica — según el autor - se basa en expediciones de largas distancias de indígenas para las salinas «libres» de control exclusivo de cualquier grupo en particular. Sin embargo, Wörrle también nota la existencia de formas de acceso a la sal que implicaban una retribución para los grupos en el ámbito de las salinas a cambio de ese recurso, pero esa variación (que él llama «formas regionales»), dada por las relaciones de tipo comercial, no la considera central (Wörrle, 1999, p. 63). De ese modo, el modelo de organización para acceder a la sal — bajo la denominación de «formas regionales»- son una derivación de la «explotación multiétnica» como forma principal, manteniéndose ambas modalidades en la dicotomía entre control/no-control de una salina por las poblaciones. De la misma forma, una explicación de ese carácter no restrictivo del modelo de «explotación multiétnica» se enlaza al tema del poder: los grupos locales no podían ejercer un «verdadero control», como consecuencia de no tener capacidad de superar escenarios de conflicto generados por la necesidad de la sal de diferentes grupos (Wörrle, 1999, p. 64). De ahí que la explotación multiétnica sería el medio más eficaz de acceso, expresando al mismo tiempo una «ética económica» en la que destaca la distribución antes que el lucro (Wörrle, 1999, p. 65).

Un argumento similar nos propone Scazzocchio, en la década de 1970, en relación a las salinas (en las que se incluye la de Callanayaku) situadas a lo largo de las fronteras tribales en la cuenca del Huallaga, las cuales eran frecuentadas gracias a caminatas (trekking) por más de un grupo (1978, p. 35). Dentro de los territorios, según la autora, ninguna unidad social intentó «controlar» las minas de sal. Por contraste, existían colonos (no-indígenas) que habrían «intentado el control de los medios de producción en algunas zonas de trekking [para el caso, una mina de sal], por ejemplo, usando barriles de metal para evaporar la sal de 
los indios» (1978, p. 35, traducción mía). Estas personas se ganaban la vida con la venta de sal en áreas que no contaban con este recurso. De este modo la autora informa este caso a partir de la diferencia entre control (no indígena) y no-control (indígena).

Bajo un enfoque que pone énfasis en la apropiación y control de lugares por grupos indígenas, Santos Granero (2006) explora el caso del sitio precolonial y colonial conocido como el Cerro de la Sal, ubicado en la frontera de varias etnias arawak (asháninca, matsigenga, yánesha) en la selva central. En su análisis, el autor resalta las operaciones simbólicas a través de las cuales los arawak configuran su territorialidad. Así, entre estas operaciones se encuentran las narraciones míticas de origen del Cerro de la Sal, entre las que destaca la de los matsigenga, según la cual la Mujer Sal (Pareni), tras un largo peregrinaje por diferentes puntos del territorio arawak junto a su hija, se convierte en el Cerro (2006, p. 105). Por su parte, los yánesha cuentan con pequeñas narraciones del origen de las variedades de sal («sal de agutí», «sal de jaguar», «sal de loro», entre otras), que surgen con el asesinato por los humanos de Posona, el Hombre Sal primordial (2006, p. 106). De manera complementaria, el autor señala como otro mecanismo de apropiación simbólica del Cerro de la Sal los rituales realizados en este lugar desde la época prehispánica por diferentes grupos andinos y amazónicos (como los de habla pano) al momento de su peregrinaje para obtener sal (2006, p. 107). De ese modo, el autor toma en cuenta en su análisis los fundamentos de formas de ocupación de un espacio también multiétnico ${ }^{40}$, pero partiendo de la lectura que los propios grupos tienen sus entornos (en este caso, las salinas).

Según lo visto en este artículo, los kichwa de Callanayaku parecen también estar interesados por el tema del control, aunque sin orientarse hacia el «control restrictivo», ni organizados bajo cualquier estructura de poder estatal. Así también, aunque el tema de la salina es fuente de un gran interés intelectual para las personas de la comunidad, la manera en que conciben su apropiación pone en juego otro tipo de operaciones. A diferencia de lo que muestra Santos Granero para el caso de los arawak con el Cerro de la Sal, en Callanayaku se presentan

40 En este articulo no se han abordado con profundidad las implicancias de la ocupación multiétnica de las minas de sal, lo que parece ser una cuestión que atraviesan las ideas de Wörrle y Santos Granero sobre el tema. Este asunto, sin embargo, no queda de lado para el caso de la mina de sal de Callanayaku, en la medida en que, en la lectura de las personas de la comunidad sobre la historia de sal, existen diacríticos distintivos en los sujetos con los cuales se relacionan. Considero que un abordaje del sentido de las relaciones multiétnicas en las minas de sal del Huallaga tendría que incluir un mayor análisis sobre las relaciones de poder entre estos sujetos, que escapa de los objetivos del presente artículo. 
operaciones diferentes de prácticas rituales o narraciones de mitos fundantes ${ }^{41}$; más bien se vuelcan hacia las relaciones sociales de su pasado reciente.

De otro lado, a diferencia de Wörrle, el tópico sobre control y dominio en el caso de Callanayaku no tendría como principio la escasez de la sal, sino la disponibilidad del recurso; es decir, el hecho de que esta pueda ser accesible o al alcance de las personas, independiente de su suficiencia.

Además, la explicación del control de la salina en Callanayaku no inicia con este principio de suficiencia (la escasez) del recurso para explicar la organización social y las formas de interacción entre diferentes grupos. Por el contrario, los relatos kichwa de Callanayaku, al resaltar la circulación de la sal a través del intercambio comercial, en cierto modo invierten los términos: el control sobre las relaciones sociales (las redes de comercio y la distribución de la sal) permite explicar la disponibilidad del recurso para los grupos interesados en este. Esto se corresponde con la idea de Brightman según la cual las prácticas hacen la propiedad (Brightman, 2010, p. 140), en el sentido de que son las acciones - ya sea de manipulación o de intercambio - las que permiten el control, la posesión o el dominio de recursos y lugares.

La circulación de sal de la mina de Callanayaku, que representa un gran propulsor de la memoria histórica para los habitantes de la comunidad, es una muestra de cómo la relación entre pueblos indígenas y los lugares en la Amazonía es fundada en el tiempo en dos sentidos: no solo porque se da en la historia, sino también porque configura la memoria de lo que supone aprovechar la sal y que esté disponible para diferentes personas.

\section{REFERENCIAS BIBLIOGRÁFICAS}

Barclay, Frederica. (2001). Cambios y continuidades en el pacto colonial en la Amazonía. El caso de los indios Chasutas del Huallaga Medio a finales del siglo XIX. Bulletin de l'Institut Français d'Études Andines 30(2), 187-210. https://doi. org/10.4000/bifea.6994

Brightman, Marc. (2010). Creativity and Control: Property in Guianese Amazonia. Journal de La Société Des Américanistes, 96(96-1), 135-167. https://doi.org/10.4000/ jsa. 11303

41 Cabe indicar que se necesitaría un mayor estudio sobre estas operaciones simbólicas entre los kichwa del Huallaga que, por ejemplo, explore con mayor sistematicidad y profundidad los significados en los relatos sobre las madres y/o guardianes de las minas de sal que cuenta la población Kichwa en San Martín. 
Caja de Depósitos y Consignaciones (Perú) y Departamento de Recaudación (1954). El Estanco de la Sal: historia, función social, económica y política del estanco: la moderna planta de refinación. Lima: Caja de Depósitos y Consignaciones, Departamento de Recaudación.

Chantre y Herrera, José. (1901). Historia de las misiones de la Compañía de Jesús en el Marañón español. Madrid, Impr. de A. Avrial. Recuperado de http://archive.org/ details/historiadelasmi00meragoog

Chaparro, Anahí y Valderrama, Miguel. (2017). Políticas de conservação e direitos territoriais dos povos indígenas: O caso da região San Martín, Perú. Habitus, 15(1), 73-92. https://doi.org/10.18224/hab.v15i1.5901

Cipolletti, María Susana. (1988). El tráfico de curare en la cuenca amazónica (siglos XVIII y XIX). Anthropos, 83(4/6), 527-540. JSTOR. Recuperado de JSTOR.

Contreras, Carlos. (2009). Crisis y reforma fiscal en el Perú, 1873-1915, del Estado rentista al Estado oligárquico. Centro de Estudios Históricos de El Colegio de México, México.

Duche Hidalgo, Carlos. (2005). Los andoas. Kandwash ajustushkani. Abya Yala.

Egerlid, Josefin. (2015). Governing indigenous territories in the Peruvian Amazon: Placing people or forest first? (Master's Thesis). Swedish University of Agricultural Sciences, Uppsala.

Gianotti, Emilio. (1997). Viajes por el Napo: Cartas de un misionero (1924-1930). Abya Yala.

Hill, Jonathan. D. (2011). Sacred landscapes as environmental histories in Lowland South America. En A. Hornborg y J. D. Hill (eds.), Ethnicity in ancient Amazonia: Reconstructing past identities from archaeology, linguistics, and ethnohistory (pp. 259-277). Colorado: University Press of Colorado.

Hirsch,Eric. y Stewart, Charles.(2005). Introduction:Ethnographies ofHistoricity. History and Anthropology, 16(3), 261-274. https://doi.org/10.1080/02757200500219289

Karsten, Rafael, Montano, María Clara, Iglesias, Genny. y Dueñas, Héctor. (2000). La vida y la cultura de los shuar: cazadores de cabezas del Amazonas occidental : la vida y la cultura de los Jíbaros del este del Ecuador. Abya Yala. Recuperado de http://digitalrepository.unm.edu/abya_yala/154

Kohn, Eduardo. (2002). Natural Engagements and Ecological Aesthetics Among the Ávila Runa of Amazonian Ecuador. University of Wisconsin, Madison.

Kohn, Eduardo. (2007). Animal masters and the ecological embedding of history among the Ávila Runa of Ecuador. En Time and memory in indigenous Amazonia: Anthropological perspectives (pp. 106-129). Gainesville: University Press of Florida. 
La Torre Silva, Ricardo J. (2016). Antonio Raimondi y el origen de la historia geográfica del Perú. Acta Herediana, 56(0), 63. https://doi.org/10.20453/ah.v56i0.2717

Marzal, Manuel. (1984). Las reducciones indígenas en la Amazonia del virreinato peruano. Amazonía Peruana, V(10), 7-45.

Maskrey, Andrew, Rojas, Josefa y Pinedo, Teócrito. (1991). Raíces y bosques: San Martín, modelo para armar. Lima: Soluciones Prácticas - ITDG.

Mezzenzana, Francesca. (2015). Living through forms: Similarity, knowledge and gender among the Pastaza Runa (Ecuadorian Amazon) (Thesis (Ph.D.), The London School of Economics and Political Science (LSE)). The London School of Economics and Political Science (LSE), London. Recuperado de http://etheses.lse. ac.uk/3181/

Miller, Joana. (2005). Antes os Brancos já existiam: Uma análise crítica do modelo do contato de Terence Turner para os Kayapó. Estudios Latinoamericanos, 25, 173-204.

Murra, John. (1975). El control vertical de un máximo de pisos ecológicos en la economía de las sociedades andinas. En J. Murra (ed.), Formaciones económicas y políticas del Mundo Andino (pp. 59-115). Lima: IEP.

Negro, Sandra. (2000). Maynas una misión entre la ilusión y el desencanto. En Marzal, Manuel y Sandra Negro (coords.), Un reino en la frontera. Las misiones jesuitas en la América colonial (pp. 185-206). Quito: Pontificia Universidad Católica del Perú, Abya-Yala.

Oberem, Udo. (2004). Trade and Trade Goods in the Ecuadorian Montaña. En P. Lyon (ed.), Native South Americans: Ethnology of the Least Known Continent (pp. 346-357). Oregon: Wipf and Stock Publishers.

Paz Soldán, Mariano. (1862). Geografía del Perú, obra póstuma del D.D. Mateo Paz Soldán. París: Librería de Fermín Didot hermanos, hijos y c.

Perez, Gino. (2017). La institucionalización del ACR Cordillera Escalera en el Perú: la desterritorialización del pueblo kichwa de San Martín (Dissertação de Mestrado, UniversidadeFederaldoSoleSudestedoPará).UniversidadeFederaldoSoleSudeste do Pará, Marabá - Pará. Recuperado de https://www.academia.edu/35752380/ LA_INSTITUCIONALIZACI\%C3\%93N_DEL_ACR_CORDILLERA_ESCALERA_EN_EL_PERU_LA_DESTERRITORIALIZACI\%C3\%93N_DEL_ PUEBLO_KICHWA_DE_SAN_MART\%C3\%8DN

Perú. Ministerio de Salud. Dirección General de Salud de las Personas. Programa Nacional de Prevención de Deficiencias de Micronutrientes (1998). Control de la deficiencia de yodo en el Perú: un modelo sostenible. Informe técnico (p. 44). Lima, Perú: Ministerio de Salud. Dirección General de Salud de las Personas. Programa Nacional de Prevención de Deficiencias de Micronutrientes. Recu- 
perado de Ministerio de Salud. Dirección General de Salud de las Personas. Programa Nacional de Prevención de Deficiencias de Micronutrientes website: http://bvs.minsa.gob.pe/local/MINSA/1102_MINSA1014.pdf

Perú. Ministerio de Salud. Programa Salud Básica para Todos (1996). Manual de procedimientos: Enfermedades transmisibles, desórdenes por deficiencia de Iodo, Diabetes Mellitus (p. 127). Lima: Ministerio de Salud. Programa Salud Básica para Todos. Recuperado de Ministerio de Salud. Programa Salud Básica para Todos website: http://bvs.minsa.gob.pe/local/MINSA/915_DGSP142-1.pdf

Pretell Zárate, Eduardo. (1989). Desórdenes por deficiencia de yodo (DDI): generalidades. Situación en el Perú (pp. 397-451). Lima: Ministerio de Salud.

Pretell Zárate, Eduardo y Higa Yamashiro, Ana María. (2008). Eliminación sostenida de los desórdenes por defíciencia de yodo en Perú: 25 años de experiencia. Acta Médica Peruana, 25(3), 128-134.

Raimondi, Antonio. (1942). Apuntes sobre la provincia litoral de Loreto. El Oriente.

Rappaport, Joanne. (2004). La geografía y la concepción de la historia de los Nasa. En A. Surrallés y P. García-Hierro, Tierra adentro: territorio indígena y percepción del entorno (pp. 173-185). Copenhage: IWGIA.

Reeve, Mary-Elizabeth. (1994). Regional Interaction in the Western Amazon: The Early Colonial Encounter and the Jesuit Years: 1538-1767. Ethnohistory, 41(1), 106-138. https://doi.org/10.2307/3536980

Reeve, Mary-Elizabeth. (2002). Los quichua del Curaray: El proceso de formación de la identidad. Quito: Editorial Abya Yala.

Rival, Laura. (2012). Trekking Through History: The Huaorani of Amazonian Ecuador. New York: Columbia University Press.

Ruiz de Pardo, Carmen. (2005). Las rebeliones antifiscales por la sal en 1896. En Historias paralelas. Actas del Primer Encuentro de Historia Perú-México. Lima: PUCP-El Colegio de Michoacán. Lima: PUCP.

Salomon, Frank. (1999). Testimonies: The making and reading of native South American historical sources. En Salomon, Frank y Stuart Schwartz (eds.), The Cambridge History of the Native Peoples of the Americas (pp. 19-95). Cambridge: Cambridge University Press.

Santos Granero, Fernando. (1985). Crónica breve de un etnocidio o la génesis del mito del «gran vacío amazónico. Amazonía Peruana, VI(11), 9-38.

Santos Granero, Fernando. (1992). Etnohistoria de la Alta Amazonia: siglo XV-XVIII. Abya Yala.

Santos Granero, Fernando. (2004a). Escribiendo la historia en el paisaje: Espacio, mitología y ritual entre la gente yanesha. En Surrallés, Alexandre y Pedro 
García-Hierro, Tierra adentro: Territorio indígena y percepción del entorno (pp. 187-217). Copenhage: IWGIA.

Santos Granero, Fernando. (2004b). Introducción. En F. Santos Granero (ed.), La conquista de los Motilones, Tabalosos, Maynas y Jibaros (p. 418, De M. de la Riva Herrera). Iquitos: CETA.

Santos-Granero, Fernando. (2006). Paisajes sagrados arahuacos: Nociones indígenas del territorio en tiempos de cambio y modernidad. Revista Andina (42), 99-124.

Scazzocchio, Francoise. (1978). Curare kills, cures and binds: Change and persistence of Indian trade in response to the contact situation in the North-western Montaña. Cambridge Anthropology, 4(3), 30-57.

Scazzocchio, Francoise. (1981). La conquête des Motilones du Huallaga Central aux XVIIe et XVIIIe siècles. Bulletin de l'Institut Français d'Études Andines, 10(34), 99-111.

Sevilla, Ximena. (2013). Kichwa organizations in the Peruvian Amazon: Twelve challenges in their quest for land rights (Thesis, University of Kansas). University of Kansas. Recuperado de https://kuscholarworks.ku.edu/handle/1808/12261

Strathern, M. (2014). Artefatos da história: Os eventos e a interpretação de imagens. En F. Ferrari (ed.) y I. Dulley (trad.), O efeito etnográfico e outros ensaios (pp. 211-229; De M. Strathern). São Paulo: Cosac Naify.

Taylor, Anne-Christine. (1999). The Western Margins of Amazonia from the Early Sixteenth to the Early Nineteenth Century. En Schwartz, Stuart y Frank Salomon, The Cambridge History of the Native Peoples of the Americas (pp. 188-256). Cambridge: Cambridge University Press.

Torres-Londoño, Fernando. (2006). Indigenuous work in the controlling dynamics of 17th century Maynas domination in Maranhão. História (São Paulo), 25(1), 15-43. https://doi.org/10.1590/S0101-90742006000100002

Torres-Londoño, Fernando. (2007). Contato, guerra e negociação: Redução e cristianização de Maynas e Jeberos pelos jesuítas na Amazônia no século XVII. História Unisinos, 11(2), 192-202. https://doi.org/10.4013/5891

Torres-Londoño, Fernando. (2012). Visiones jesuíticas del Amazonas en la Colonia: De la misión como dominio espiritual a la exploración de las riquezas del río vistas como tesoro. Anuario Colombiano de Historia Social y de la Cultura, 39(1), 183-213.

Uzendoski, Michael. (2014). Analogic Alterity: The Dialogics of Life of Amazonian Kichwa Mythology in Comparison with Tupi Guaraní (Mbyá) Creation Stories. Tipiti: Journal of the Society for the Anthropology of Lowland South America, $12(1), 28-47$. 
Valderrama, Miguel. (2019). O sal da Montanha. Notas etnográficas sobre relações de domínio e a circulação do sal numa aldeia do Bajo Huallaga na Amazônia peruana (Dissertação de Mestrado). Universidade Federal Fluminense, Niterói - RJ.

Wörrle, Bernhard. (1999). De la cocina a la brujería: La sal entre indígenas y mestizos en América Latina. Abya Yala. Recuperado de http://digitalrepository.unm.edu/ abya_yala/66

Zapata, Antonio. (2006). Instituciones de control del Estado peruano: historia y políticas en la GCR, SBS y SUNAT (p. 188). Instituto de Estudios Peruanos (IEP); Consorcio de Investigación Económica y Social (CIES). 